\title{
LA TELEVISIÓN, MEDIADORA ENTRE CONSUMISMO Y OBESIDAD
}

\section{THE TELEVISION, MEDIATOR BETWEEN CONSUMERISM AND OBESITY}

\author{
Arturo Moreno L., Luis Toro Z. \\ Escuela de Ciencias de la Comunicación, Facultad de Medicina, \\ Universidad Autónoma de San Luis Potosí (UASLP), México.
}

\begin{abstract}
In San Luis Potosi, Mexico, an investigation about the TV as mediator of the obesity phenomenon was performed. This investigation was applied to children between six and thirteen years old, who were studying in elementary schools in the urban zone of the city and who came from medium class families. We applied four techniques of investigation: poll, discussion group, personal interview and content's analysis. These techniques are used in quantitative and qualitative form by communication scientists, the first one (quantitative) to obtain hard data, and the next for getting information which is occult in mental representations and in the speech of individuals. It was proved that the overweight and obesity rate were low in the sample of 484 children. However, a high use of $T V$ was related to a higher consumption of fats and sugar and a higher consumption of "junk food.", proving the consumerism phenomenon. The consumerism, in both of its variants, was widely demonstrated in every single technique applied and visualized as a part of infant culture. In fact, TV is a mediator between the obesity and consumerism, part of a cultural system derived from the neoliberal and global system. Consumerism and obesity are related in an inherent way: any of them could not exist without the other. Children are caught by images and televise discurse which are daily reproduced in their social environment. They are a new generation in which we need to work on, studying and controlling these phenomenon or they may cause terrible consequences in a very near future.
\end{abstract}

Key words: Television; obesity; children; mediation; consumerism.

Este trabajo fue recibido el 16 de Septiembre de 2008 y aceptado para ser publicado el 20 de Enero de 2009.

\section{INTRODUCCIÓN}

Con el propósito de contribuir a la realización de los estudios de comunicación en San Luis Potosí se aborda un fenómeno social compartido desde la perspectiva de la ciencia médica y la comunicacional en una alianza que, lejos de caber con calzador, compenetró a la medida, avaló y arrojo aun más luz sobre esta gran pandemia, antecedente y consecuente de males que son padecidos a todas las edades: el sobrepeso y la obesidad.

El porcentaje de niños obesos que en la muestra se esperaba encontrar, coincidió con estudios hechos por la Facultad de Medicina de la Universidad Autónoma de San Luis Potosí1; no obstante, la estadística indica que el problema puede ir en aumento en la pubertad. A esta problemática se le añade un poderoso catalizador que contribuyó a incrementarla: la Televisión, el más poderoso sistema de información e intercambio simbólico que existe en México.

La televisión es el medio de comunicación por excelencia, de la cual crea y se involucra en los niveles micro y macro sociológicos que conforman el mundo actual, dada la gran cantidad de información que un sólo canal puede manejar y por la facilidad de su consumo, ya que éste puede ser efectuado al reunir en un solo receptor voz e imagen.

Sin afán de presunción, sirva el presente documento a investigadores, estudiantes y profesionales de la comunicación y medicina a fin de ahondar sobre vetas y 
perspectivas de las enfermedades de sobrepeso y alimentación. El objetivo es demostrar que tanto el consumo televisivo, así como el consumo de alimentos frente a ésta, propicia la obesidad en cualquiera de sus niveles, así también cómo la televisión propone a los niños un estilo de vida consumista tanto alimenticio como televisivo. Estos objetivos obedecen a que en México se calcula que existen aproximadamente 35 millones de obesos, lo que representa el $24.4 \%$ de la población según el Instituto de Salud Pública en México, el 24\% de los niños fue clasificado como obeso ${ }^{2}$.

Los resultados del presente estudio tienen un interés manifiesto en alertar a padres de familia, maestros y a toda la comunidad científica acerca de un problema de funestas consecuencias dentro del corto plazo, y cuyas raíces están echadas en la desinformación y en los excesos de los medios masivos. Ante tal precepto se analizaron cuatro tipos de cultura (cultura mercantilista, antropológica, globalizada y consumista), donde la misma sociedad, ha ido transformando consciente e inconscientemente y se involucra con la propuesta televisiva y viceversa.

\section{METODOLOGÍA}

Se estudiaron niños de ambos sexos, con una edad promedio de 6 a 13 años de escuelas primarias en la zona urbana de la ciudad de San Luis Potosí divididos en AGEBS3 (áreas geoestadísticas básicas) y cuyas familias tuvieron un ingreso de más de 2 y hasta 5 salarios mínimos diarios al mes (por trabajo, haciendo una aproximación a la clase media), tomando en cuenta un salario mínimo de $\$ 45 .^{\circ}$ pesos mexicanos por jornada, equivalente a $\$ 4$ dólares americanos (1 dólar americano, cotizado en 11 pesos mexicanos, al mes de Marzo del 2004).

Aplicación estadística: Tomamos la cifra de los niños que viven en dichas familias como nuestra $\mathrm{N}$ (universo) y aplicamos la fórmula:

$$
\mathrm{n}=\frac{\mathrm{N} \mathrm{pq}}{\frac{\left(\mathrm{ME}^{2}(\mathrm{~N}-1)\right)+\mathrm{PQ}}{\mathrm{NC}^{2}}}
$$

Utilizada para obtener cualquier tipo de muestra con un grado de confiabilidad de $+-5 \%$ dando un tamaño de muestra de 484 unidades de encuesta ${ }^{4}$, y donde:

$\mathrm{n}=$ tamaño de la muestra

$\mathrm{p}=$ probabilidad de ocurrencia (homogeneidad del fenómeno)
$\mathrm{Me}=$ margen de error o precisión. La probabilidad \pm $\mathrm{N}=$ tamaño del universo

$\mathrm{q}=$ probabilidad de no ocurrencia (1-p)

$\mathrm{Nc}=$ nivel de confianza o exactitud.

En base a los resultados del tamaño de la muestra, los cuales fueron 484 u de encuesta, a su recorte espacial en zonas urbanas de la ciudad de S.L.P, y mapas de AGEBS* del INEGI3 se inició el presente estudio.

Las técnicas de investigación aplicadas fueron 4

Encuesta $^{4}$. Del tipo descriptiva. "El propósito de éstas fue describir con precisión las características del fenómeno observado". Se aplicó en un periodo que comenzó en Mayo a Julio del 2004.

Entrevista en profundidad". "La entrevista es un intercambio verbal, de carácter privado y cordial, donde una persona cuenta su historia, da su versión de los hechos y responde a preguntas relacionadas con un problema específico". Se aplicó en Agosto del 2004.

Grupo de discusión ${ }^{4}$. Esta técnica "trabaja sobre la reducción crítica de los contenidos, mismos que se producen en un discurso grupal. Se aplicó en Agosto de 2004.

Análisis de contenido ${ }^{4}$. Se realizó subsecuente de las otras técnicas, y se analizó el programa más anclado en la conciencia de los niños, según los resultados de las otras técnicas. Se aplicó en Agosto y Septiembre del 2004.

Mapa por Valor. El mapa que se muestra a continuación, describe el criterio de hogares donde hay un ingreso de más de 2 y hasta 5 salarios mínimos por trabajo al mes, en la ciudad de San Luis Potosí, cabecera municipal (gráfica 1).

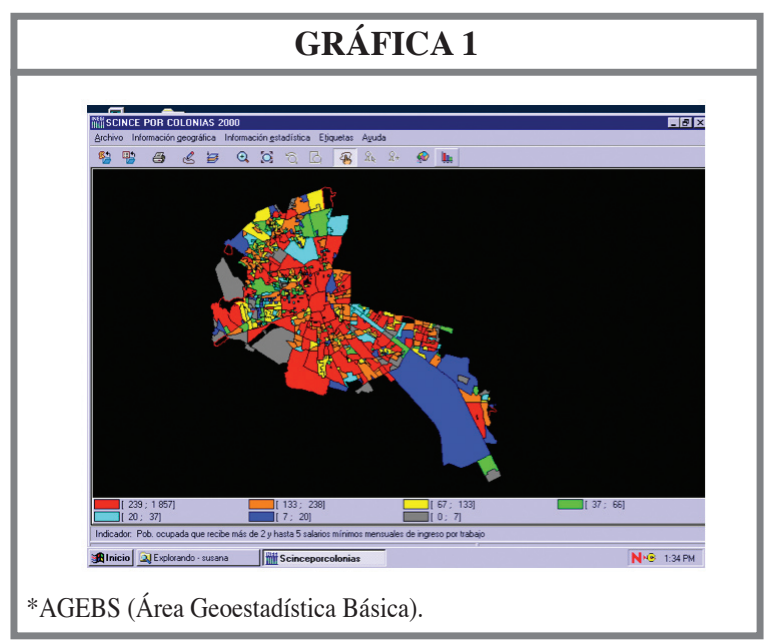

1. En un estudio realizado en el municipio de San Luis Potosí, de una muestra de 430 niños obtenida entre la población rural y urbana de la ciudad, se detectó que el $5.2 \%$ de la población infantil circula con IMC>25 y el $3.4 \%$ presentó cifras de IMC >27, correspondiendo a obesidad ${ }^{15}$ 


\section{RESULTADOS \\ "La tragedia pueril"}

Análisis cualitativo de la encuesta, entrevista en profundidad y análisis de contenido

La edad de los encuestados osciló entre los 6 y los 13 años (como se aprecia en la gráfica 2). El 52.8\% fue femenino y el $47.2 \%$ masculino (como se aprecia en la gráfica 3).

Las preguntas mas relevantes fueron:

1.- Cuando comes, ¿ves TV.?

2.- ¿Te gusta comer cuando ves TV.?

4.- ¿Qué tipo de programas te gusta ver?, (Puedes marcar más de una opción)

5.- ¿Cuántas horas ves TV.?

6.- ¿Dónde y cómo ves TV.?, (Puedes marcar mas de una opción)

8.- Escribe 3 de los personajes que salen en TV., y que te gustan más:

11.- ¿Cómo te gusta que sean las personas que salen en TV., o en comerciales? (Puedes marcar más de una opción)
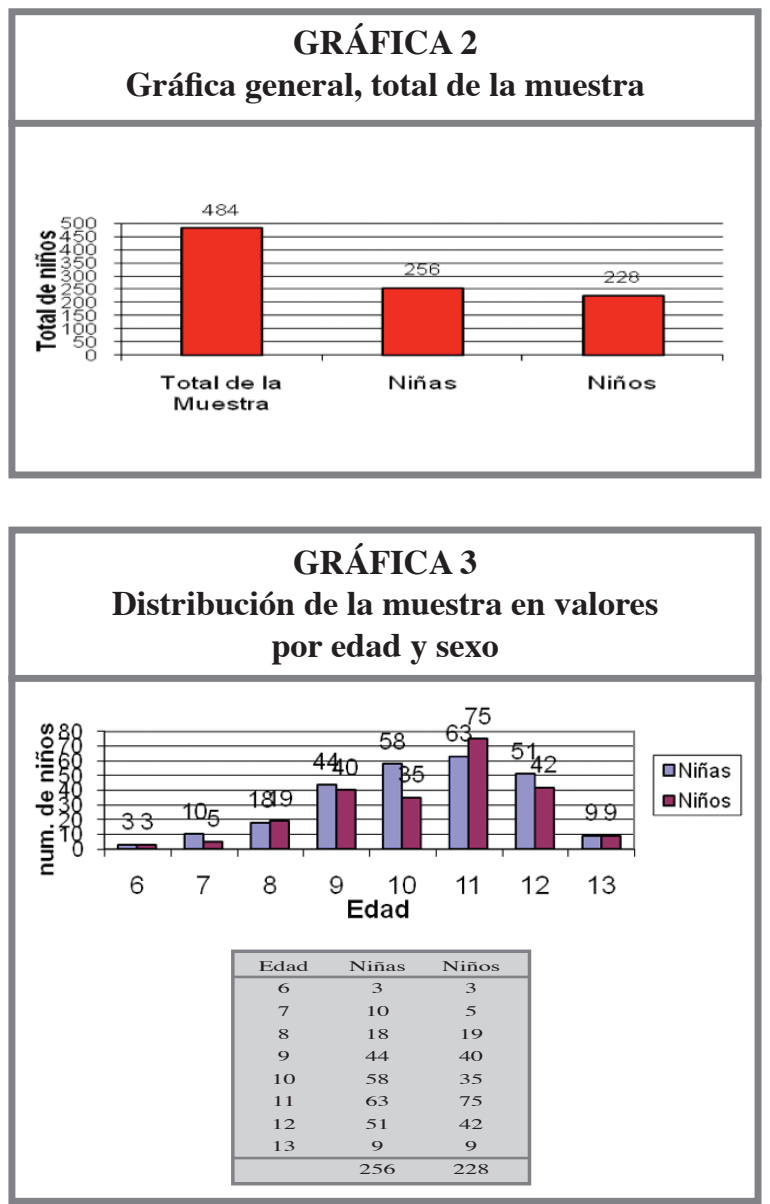

Las encuestas nos muestran que la vida sedentaria se apropia cada vez más de los menores, los resultados señalan que al 97\% de los infantes les gusta ver televisión y, que un $81 \%$ ven televisión cuando comen (como se aprecia en la gráfica número 4); y $80 \%$ comen cuando ven TV (gráfica 5).

Los niños son el blanco perfecto para los profesionales de la publicidad que, en aras de ganarse muchos dólares/pesos con la exhibición de sus comerciales, no les importa el daño a nivel físico y psicológico que les ocasionan. Todas las representaciones de la programación y la publicidad televisiva exacerban el consumismo tanto alimenticio como televisivo.

Los niños gustan más por ver caricaturas y series, mientras las niñas telenovelas, entre ambos destacan $51 \%$ las caricaturas y las series ante $28 \%$ los programas y las telenovelas (como se aprecia en la gráfica número 6); esto connota al crecimiento de un imaginario más realista para los varones mientras que para las niñas más idealista; el "príncipe azul", representa una imagen falsa; en cambio, programas culturales y competencias deportivas son parte fundamental de una visión ganadora, sana

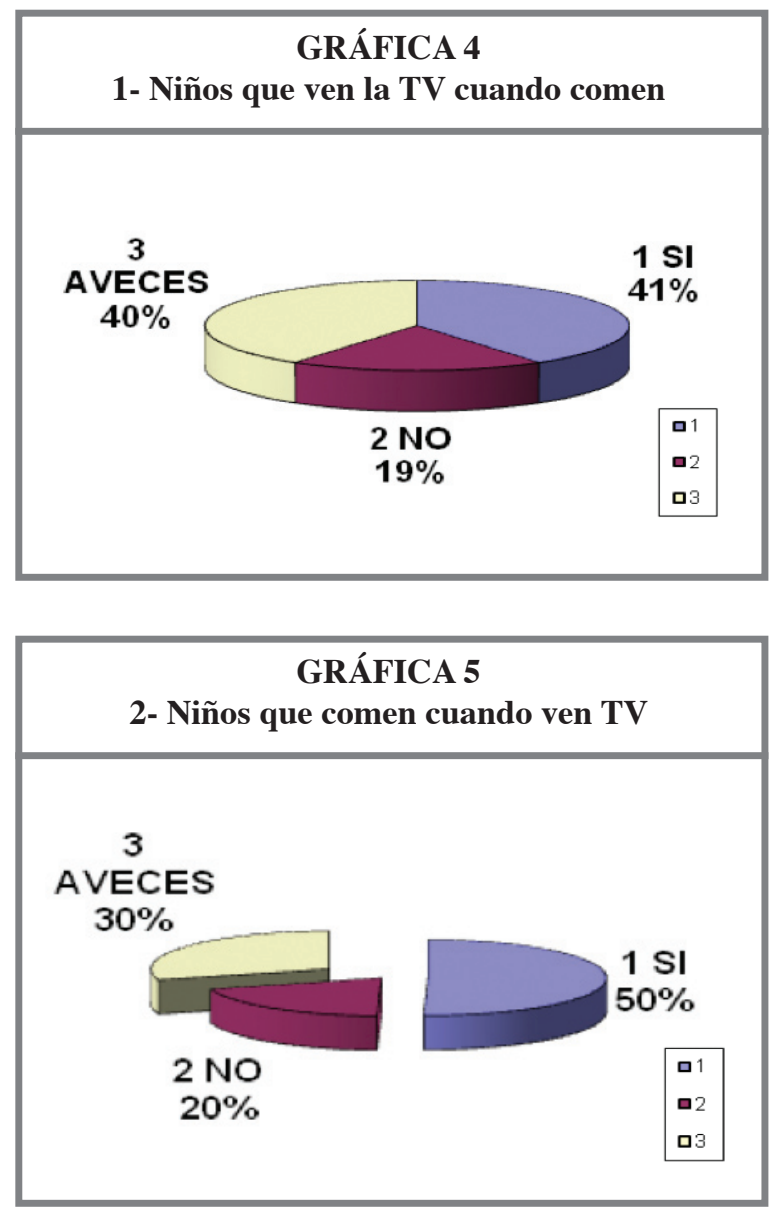


y activa; no deficiente, sedentaria y culturalmente pobre. Violencia, poder y competencia como espectáculo para los hombres, sufrimiento, lágrimas y vida color de rosa para las mujeres.

El $41 \%$ de los entrevistados se posan de 1 a 3 horas frente al aparato, mientras el $29 \%$ más de tres horas, cediéndole así su conciencia a ese monstruo televisivo (gráficas 7 y 8).

El trinomio familia-TV-niño es un caldo de cultivo perfecto para el cometido de la programación: infundir en el ideal del niño la identidad de éste con los personajes representados; el entramado de las interacciones escénicas infantiles son reflejo de las pretensiones de las superestructuras sociopolíticas de los intereses del aparato de dominio 5 .

La producción estadounidense es por excelencia la más vista con $54 \%$ por encima de la oriental con $16 \%$, aún cuando la televisión mexicana no produce dibujos animados en general obtiene el $30 \%$, con sus programas de concursos, telenovelas y mini series (como se aprecia en la gráfica número 9); programándose en horarios de la ingesta (15:00 a 17:00 hrs.) de alimentos, todos los

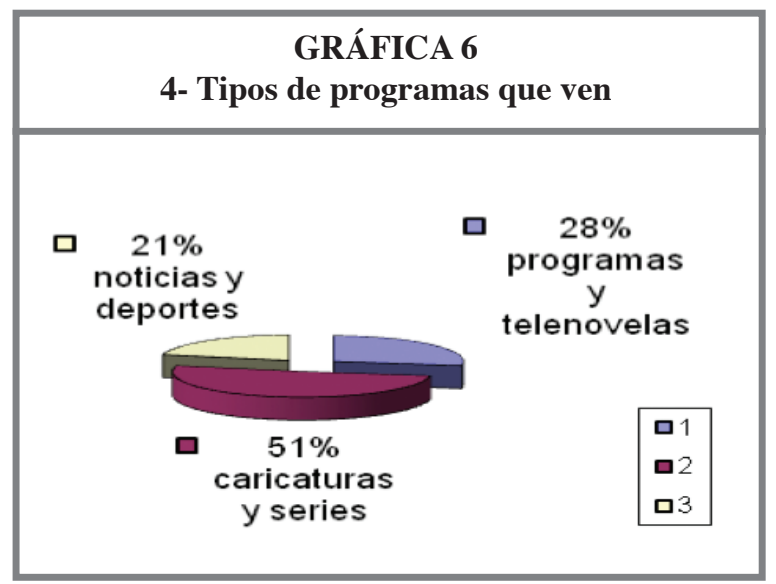

GRÁFICA 7

\section{5- Horas diarias frente a la TV}

口 Más de 3 $29 \%$

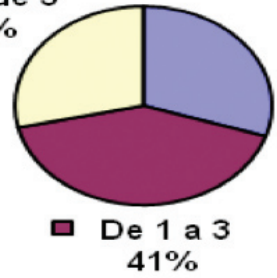

M Menos de una. $30 \%$ sentidos se orientan hacia esa conducta, menoscabando la capacidad de discernimiento, análisis y crítica de los contenidos programáticos y de marketing. Concluimos que el niño es totalmente susceptible al bombardeo sistemático de las imágenes de los programas y los comerciales.

Para finalizar este breve pero sustancial análisis, los resultados dicen que la hegemonía de la imagen es un hecho, el Homo Videns de Sartori está presente y esto queda demostrado, todos los varones y las varonesas destacaron que en su ideal, las personas deben ser rubias, altas y delgadas, por encima de morenas, altas y delgadas, y también bajitas, robustas y morenas (gráfica 10).

Lo que concluimos que la verdadera lucha que se está librando en estos tiempos es el dominio de la raza, los mensajes nos llegan como órdenes superiores: ¡ sólo algunos son "exitosos"!, como el estereotipo de persona: rubia, alta y delgada; los arquetipos "moreno", "obeso" y "bajo de estatura", obedecen a razonamientos discursivos de inferioridad.

Si la curva estadística señala que los menores que
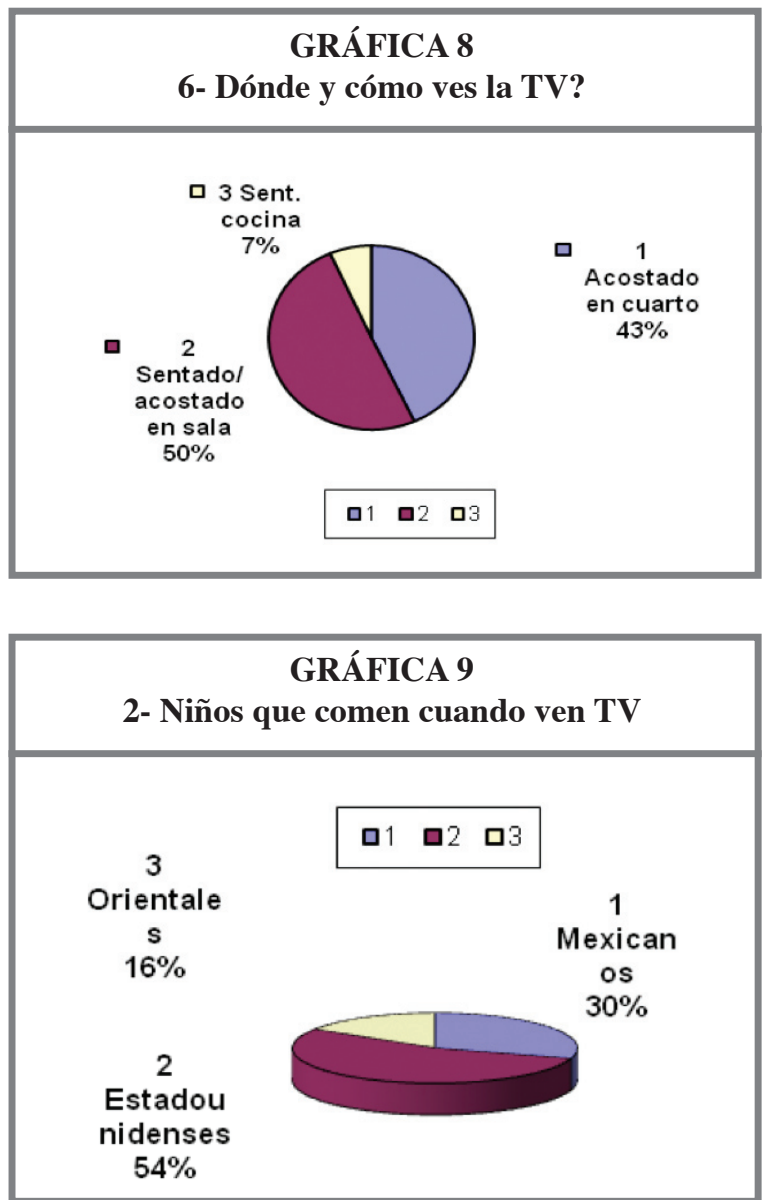
son formados por la televisión de ahora serán los obesos de mañana, entonces la televisión es mediadora entre consumismo y obesidad (como se aprecia en las gráficas número 11 y 12).

En la segunda técnica, se entrevistó a una persona del sexo femenino, de veintidós años de edad, soltera y siendo estudiante universitaria, en la ciudad de San Luis Potosí. Los resultados de la entrevista en profundidad, se fundamentaron en teorías de la personalidad, psicoanálisis y algunas corrientes comunicológicas. En base a su discurso, se expone lo siguiente:

Se percibe a si misma sin ningún tipo de problema de salud, con características de sociabilidad, de carácter explosivo y difícil, rencoroso, sensible, obsesivo, con poca tolerancia a la frustración, celosa y en ocasiones insegura. Ella se relaciona con la televisión de manera compulsiva, pues le encanta ver la televisión por periodos prolongados: "veo televisión, los medios de comunicación me matan, me gusta saturarme de información", el sedentarismo se presenta como parte de su estilo de vida: "no practico ningún deporte, sólo camino un poco", la cotidianeidad contiene partículas
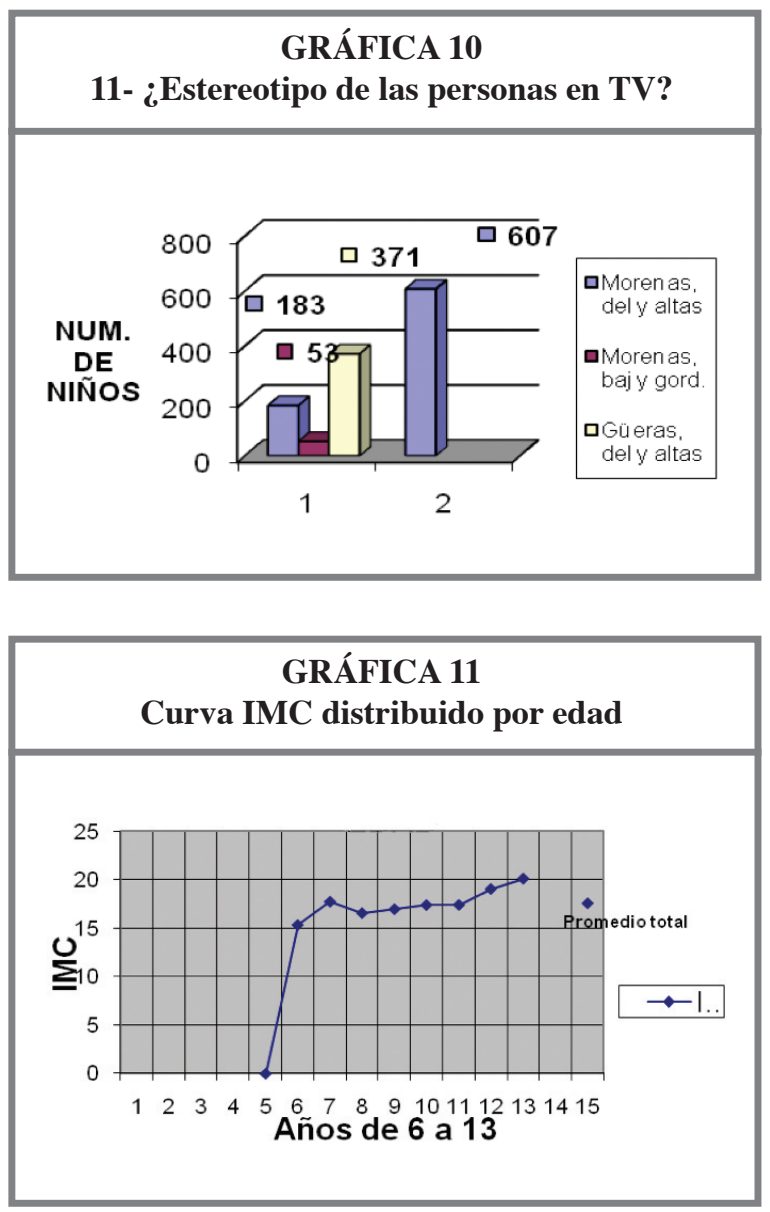

sedentarias, las cuales impulsan una personalidad insegura y paradójicamente huraña: "mis actividades en un día normal son ir a la escuela, hablar por teléfono, ver televisión, a mí sí, la verdad, los medios de comunicación me matan", agregando que su discurso fue muy cortado por muletillas cuando se trató de hilar sus actividades con su alimentación, ésta la basa en mucha glucosa, "ponme chocolates y me matas, los chocolates son mi perdición, sí, mi perdición”, manifestó nuestra entrevistada. Cuando ella se aboca a definir la dualidad obeso-delgado, expresa varios superlativos a favor del concepto delgado "flaco, flaquísimo" (como dice ella), mientras que casi no se aventura a definir el concepto obeso; la entrevistada sólo reaccionó hostilmente cuando se tocó el tema de su conocimiento acerca de los padecimientos que provoca la obesidad y también en aquel momento cuando se le preguntó si acaso sentía remordimiento después de comer de más.

En la tercera técnica se obtuvieron los siguientes resultados por medio de detonantes, los cuales se mencionan para una mayor apreciación, éstos detonantes fueron: televisión, refrescos (sodas), papas, papas "sabritas" (marca comercial), obesos, quelites, "cangreburguer" (ícono televisivo) y "MacDonald`s" (marca comercial). Lo que se obtuvo en el discurso de los niños fue igual al metalenguaje utilizado en la publicidad por ellos vista: lo que se dice y se expresa en una imagen es mostrado por lo que no se dice pero también se expresa de manera cognitiva, no auditiva ni visual; a los niños les gustaron aquellos alimentos anunciados en TV indistintamente de su nutrición, no así los vegetales, los cuales aborrecen, y desprecian ignorando sus contenidos nutricionales.

Los códigos que mediatiza la televisión, fueron recepcionados y decodificados por el mercado infantil, se aprueban socialmente y la masa social que se teje diariamente, reproduce los mensajes adquiridos para el

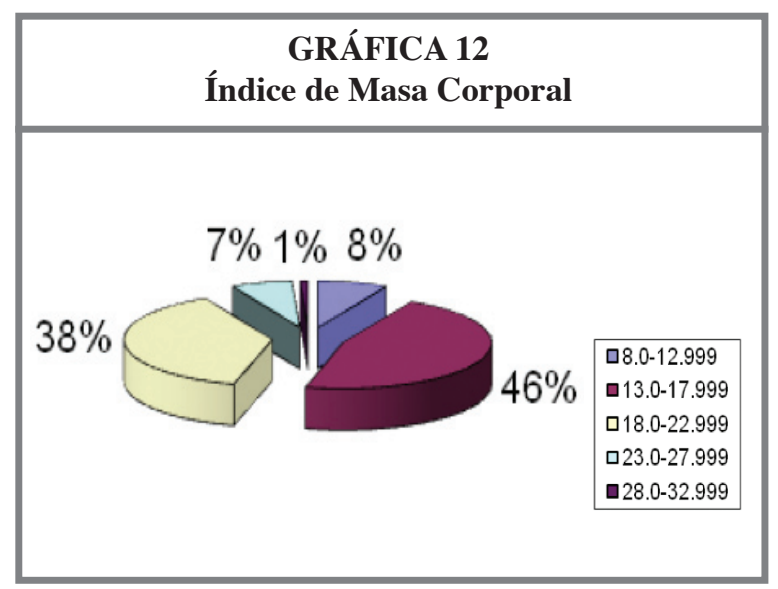


consumo de un producto televisivo o alimenticio, "cangreburguer", un icono de la actualidad de la mediación televisiva, consumo y cultura infantil, anclado hasta la conciencia de los niños; cuando gran parte del mensaje publicitario invita a la experiencia de probar, más que de consumir, cuando uno de los objetivos del mensaje no es agradar en sus contenidos sino imprimirlos mentalmente.

Por último, los resultados obtenidos en la última técnica de investigación, el análisis de contenido de los programas televisivos más vistos por los niños según los resultados cuantitativos de la encuesta, indican que el animar objetos o el "revivirlos" con características humanas, constituye uno de los mecanismos de proyección más grandes de la historia del hombre desde las mitologías griega y romana, así, el humano se libera de toda la carga psíquica de sus complejos, miedos y dispositivos de conducta. En este capítulo el tema fue el amor; se intenta promover esa misma ideología con los niños, y así se liga a un personaje admirado por ellos, el cual detenta todas las virtudes humanas: amor, nobleza y fraternidad, en tal intensidad que toca las fibras más sensibles del público infantil, y éste, asimila al consumo alimenticio como parte de otra virtud.

El consumo alimenticio, propuesto en la gran cantidad de hamburguesas que se hicieron en este capítulo, es reforzado por la abundante barra publicitaria de golosinas y botanas, donde el más mínimo movimiento mental, desde un parpadeo hasta el vislumbro del control de la televisión se hará siempre basado en el consumismo alimenticio y televisivo, lastre entrañable de la conciencia vapuleada de los infantes.

\section{CONCLUSIONES}

La presente investigación desentrañó los más recónditos secretos de ésta patología que consume a los niños día con día y se involucra en un juego niño-televisiónconsumo-obesidad. Con esto, contribuye los esfuerzos de la comunidad médica para tratar esta patología, subrayando y visualizando las relaciones entre la obesidad y el acto de ver televisión.

La televisión es un instrumento que incide de manera importante en el desarrollo de las enfermedades de la alimentación como el sobrepeso y la obesidad. Urge rescatar la misión histórica de los medios públicos de comunicación colectiva para reequilibrar la desproporción estructural en todos los sentidos. Los humanos merecemos una vida diferente que transforme el modelo de las últimas décadas y provea a la humanidad de una conciencia colectiva que le permita tener mejores niveles de vida, por lo tanto hay reconocer y alertar acerca del peligro que representa para la salud mental y física que los medios masivos de comunicación, en especial la televisión se hayan convertido en el centro del poder ideológico y político.

Los espacios recreativos, se han devaluado por debajo a los tiempos en donde la televisión programa al público infantil por medio de sus contenidos, quienes orillados a romper con los esquemas de los rituales de la tradicional familia, buscan un modelo de socialización, comunicación y aprendizaje, encontrándola dentro de las alternativas que poco a poco se reducen a simples mecanismos cotidianos propuestos por quien controla el poder ideológico, al mismo tiempo que los infantes construyen su propia dialéctica en su crecimiento biológico y sociocultural, propuesta y sistematizada por la televisión, que recrea y programa al adulto del mañana.

Este estudio comprobó que la ciencia social y la comunicología pueden desmembrar problemas de salud pública que eran estudiados y atacados bajo una disciplina única; ambas pueden llegar a niveles antes poco recorridos, es por ello que esta investigación descubrió científicamente que la televisión actual es una fuente de poder la cual contribuye de manera ideológica al consumo alimenticio y televisivo, dañando la salud mental y física de los infantes, utilizando así la pandemia de la obesidad como un método comercializador, un producto más para vender sus propios contenidos. En la actualidad, así como buscamos muchas soluciones para atacar el problema de la obesidad que involucra a toda una sociedad mundial, intentemos una reestructuración de los contenidos televisivos y un rediseño de la propias formas de dominio cultural, para mejorar lo que la comunidad científica (divulgadores y científicos) buscamos, una mejor civilización.

\section{RESUMEN}

En la ciudad de San Luis Potosí, México, se realizó una investigación estudiando el fenómeno de la obesidad y la mediación televisiva, con niños de 6 a 13 años en escuelas primarias de la zona urbana, dentro de la clase socioeconómica "media", usando 4 técnicas de investigación (encuesta, grupo de discusión, entrevista a profundidad y análisis de contenido), las cuáles se usan en las ciencias de la comunicación, de manera cuantitativa y cualitativa, la primera para obtener datos duros y la segunda para aquella información que se oculta en las representaciones mentales y sus discursos. Se comprobó que los índices de sobrepeso y obesidad como resultado en la muestra de los 484 niños, son bajos; sin embargo, un alto consumo televisivo y alimenticio (lípidos y azúcares), se hace presente de manera constante y creciente; es decir, a mayor edad, mayor consumo (más televisión, más comida "chatarra"), evidenciando el fenómeno del 
"consumismo". El consumismo, tanto alimenticio como en la televisivo fue un fenómeno ampliamente demostrado en todas y cada una de las técnicas aplicadas y visualizadas como parte de una misma cultura. La televisión es mediadora entre obesidad, problema de salud mundial y el consumismo, sistema cultural derivado del sistema neoliberal y globalizado; consumismo y obesidad están relacionados de manera intrínseca, uno sin el otro no puede existir. Los niños, enajenados por imágenes y discursos televisivos, mismos que son reproducidos cotidianamente en sus relaciones interpersonales; son parte de una nueva generación que si bien no ocupamos la comunidad científica por estudiar y controlar dichos fenómenos, éstos atraerán terribles consecuencias en un futuro muy próximo.

Palabras clave: Televisión; obesidad; niños; mediación; consumismo.

Dirigir la correspondencia a:

Arturo Moreno L.

Escuela de Ciencias de la Comunicación

Facultad de Medicina
Universidad Autónoma de San Luis de Potosí México

Fax: 444-8-25-01-82

E-mail: arturomoreno@hotmail.com

\section{BIBLIOGRAFÍA}

1. M.C. Aradillas García Celia; Dr. Quibrera Ricardo. Investigación: "Resistencia en los niveles de la insulina en niños". Facultad de Medicina. San Luis Potosí, S.L.P. México. 2003.

2. Sitio www.fundar.org.mx/seguimiento/sc_salud/ salud_iniciativas_2.htm.2004.

3. INEGI (Instituto Nacional de Estadística, Geografía e Informática).Censo poblacional. División socioeconómica: "Determinando el ingreso familiar de 3 a 5 salarios mínimos diarios por trabajo mensuales". México. 2000.

4. Galindo, Cáceres Jesús. Técnicas de Investigación en Sociedad, Cultura y Comunicación. Editorial: Prentice Hall. 1998.

5. Althusser, Louis. Ideología y aparatos Ideológicos del Estado, Editorial Nueva visión. 1970. 